\title{
PHASE EQUILIBRIA AND THERMODYNAMICS: MEASUREMENTS
}

\author{
Kurt L. Komarek and Herbert Ipser \\ Institute of Inorganic Chemistry, University of Vienna, \\ A-1090 Vienna, Waehringerstr. 42, Austria
}

\begin{abstract}
Recent developments of experimental techniques for the investigation of phase diagrams and for the measurement of thermodynamic quantities of metallic and ceramic materials at high temperatures are reviewed. Special emphasis is placed on the generation and the measurement of high temperatures, on thermoanalytical techniques, on calorimetry of reacting and non-reacting systems, emf and Knudsen effusion methods.
\end{abstract}

\section{INTRODUCTION}

Phase diagrams and thermodynamic properties are closely interrelated, and a knowledge of both allows an exact definition of the phase composition at a certain temperature, pressure and mole fraction which in turn determines many properties of a specified material. Especially chemistry and materials science at high temperature rely heavily on phase diagrams and on thermodynamic properties of materials, and a discussion of the experimental methods is clearly of interest to scientists and engineers working in this field. In a review paper of limited length only a short overview can be given, with emphasis on more recent developments. In general one can say that advancements in the past few years were due less to radically new techniques than to automated control, data acquisition, and processing with laboratory computers and microprocessors. For a more comprehensive treatment, previous articles by the authors on experimental methods of the determination of phase diagrams (Ref. 1) and of thermodynamic properties (Ref. 2-5) should be consulted. At first methods related to phase diagrams will be discussed, since some like generation and measurement of temperatures also apply to thermodynamic studies, and then techniques related to themodynamic properties will be treated.

\section{PHASE DIAGRANIS: EXPERIMENTAL METHODS}

Although considerable advances have been made within the last two decades in multicomponent phase diagram calculations, especially by the CALPHAD group (e.g. Ref. 6, 7), experiments are still the most important source of information for binary and ternary phase diagrams. Results have been published in a number of books (Ref. 8-11), and recently a joint ASM-NBS Alloy Phase Diagram Program has begun to critically evaluate and compile experimental data on phase diagrams with the compilations being published regularly in the Bulletin of Alloy Phase Diagrams. Several laboratories have also instituted programs to store experimental information in data banks.

\section{Generation of high temperatures}

Most commonly samples are brought to high temperatures by electrical furnaces. With wires or bands of iron-chromium-aluminum alloys (e.g. Kanthal) temperatures up to $1600 \mathrm{~K}$ can be reached. The use of noble metals increases the temperature limit up to about $1900 \mathrm{~K}$ with platinum, $2100 \mathrm{~K}$ with rhodium, and $2400 \mathrm{~K}$ with iridium. Even higher temperatures can be obtained with molybdenum (about 2500K), tantalum (2800K) and tungsten $(3500 \mathrm{~K})$, but these elements can only be heated in an oxygen-free atmosphere or in vacuum. Rods or tubes of silicon carbide ( $\mathrm{SiC}$ ) or molybdenum disilicide (NOSi${ }_{2}$, e.g. Kanthal-Super) can be used in air up to about 1800 and $2000 \mathrm{~K}$, resp. Temperatures of $3300 \mathrm{~K}$ and even higher can be reached by passing electrical current through tubes of graphite or tungsten, again in oxygen-free atmosphere. Similarly, refractory oxide tubes like stabilized zirconia can be used as heating elements in 
air if the material becomes electrically conducting at elevated temperatures. Induction furnaces depending on construction and on the material properties operate up to $3300 \mathrm{~K}$, electric arc furnaces up to even higher temperatures.

In the Pirani method electrically conducting samples are heated practically container-free to very high temperatures by direct passage of a current. Rudy and coworkers (12-14) have developed such a furnace for the study of phase diagrams of high-melting binary and higher-component systems especially of transition metal carbides up to $4300 \mathrm{~K}$. Vereshchagin and Fateeva (15) described two pressurized furnaces for pressures up to 3 and $100 \mathrm{kbar}$, resp., in which samples are heated by passing alternating current for some seconds to reach temperatures up to about 5000K. Popova et al (16) used these furnaces to investigate phase diagrams with components of very different vapor pressures and melting points, e.g. tungsten-gallium. A closely related technique which may have some application for the determination of phase diagrams at very high temperatures is the fast-pulse-heating method in which electrically conducting samples are heated by an extremely short electric current pulse (Ref. 17-20). The sample might be a tube (Ref. 18) or a wire or a band (Ref. 20), and heating rates might be between 3000 and $9000 \mathrm{Ks}^{-1}$ for 0.3 to $0.9 \mathrm{~s}$ (Ref. 18) up to $10^{9} \mathrm{Ks}^{-1}$ for $1.5 \mu \mathrm{s}$ (Ref. 20). Thermophysical properties but also melting and solid-solid transition temperatures of high-melting metals or alloys (e.g. Ref. 21, 22) and of uranium dioxide (Ref. 18) have been determined.

High temperatures can also be produced by focusing the radiation of a light source (sun or artificial) onto the material, heating the sample containerfree in any kind of atmosphere. The theoretical upper temperature limit is given by the temperature of the source. Solar furnace facilities have been applied to the investigation of oxide phase diagrams mainly by Foex, Coutures and coworkers in France $(23-25)$ and by Nizuno, Yamada, Noguchi and coworkers in Japan (26). The sample is heated in an evacuated or inert gas-filled pyrex container focusing the solar radiation by spherical or parabolic mirrors, and it can be either quenched or splat-cooled (Ref. 23, 24) or studied at temperature. Imaging furnaces with an electric arc as light source and a temperature range of 2500-4000K have been commercially available for more than twenty years (Ref. 27). Kishi et al(28) applied radiation heating to thermal analysis using an infrared-image furnace with two or four halogen lamps. The upper temperature limit with four lamps is around $1700 \mathrm{~K}$ with heating and cooling rates between 0.6 and $1000 \mathrm{Ks}^{-1}$, and an accuracy of \pm 0.1 to $\pm 0.5 \mathrm{~K}$ depending on the heating rate. Application of this type of furnace for thermogravimetry (up to 1600K) and for dilatometry (up to 1500K) has been described by Maesono et al $(29,30)$. A radiation-heated DTA system with one halogen lamp (maximum power consumption 100W) as a heat source and an upper temperature limit of $1100 \mathrm{~K}$ with a possible extension up to $1800 \mathrm{~K}$ was described by Emmerich et al (31).

With the application of lasers temperatures higher than $5000 \mathrm{~K}$ can be reached.

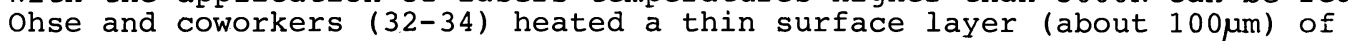
uranium dioxide or uranium-plutonium dioxide by a $100 \mu$ s pulse of a neodymiumdoped YAG-laser to measure vapor pressures up to $5000 \mathrm{~K}$. A very similar method was employed by Nordine et al (35). The phase diagram of carbon near the solid-liquid-gas triple point was studied by sheindlin and coworkers (36, 37) by heating the sample with either a high stability carbon dioxide or a highpower YAG-laser in a pressure chamber where pressures up to $3 \mathrm{kbar}$ could be generated in various gases. Extremely constant temperatures can be achieved with a heatpipe furnace which is in principle an evacuated chamber with inside walls lined by a capillary structure (wick) saturated with a volatile working fluid. Finlay and Green (38) reviewed the construction and possible applications of heat pipes and described attempts to extend the principle up to more than $2300 \mathrm{~K}$. A heat pipe furnace for temperatures between 873 and $1273 \mathrm{~K}$ was constructed by Baumullier et al (39) with a temperature constancy of $0.1 \mathrm{~K}$ within $5 \mathrm{~h}$, and $0.05 \mathrm{~K}$ over $145 \mathrm{~mm}$. An even more accurate gas-controlled furnace with sodium as working fluid was described by Bassani et al (40) who observed at $1123 \mathrm{~K}$ variations of less than $0.005 \mathrm{~K}$ over more than $300 \mathrm{~mm}$.

\section{Measurement of temperature}

The primary reference points for the standardization of temperature measuring devices are defined by the "International Practical Temperature Scale 1968" (IPTS-68). Between the melting point of antimony of $903.905 \mathrm{~K}$ (Ref. 41) and the melting point of gold of $1337.58 \mathrm{~K}$, the Pt-Pt1 $0 \% \mathrm{Rh}$ thermocouple is the 
standard thermometer; above this temperature Planck's radiation law serves for the verification of the IPTS-68. There are a number of secondary reference temperatures to facilitate standardization between the frequently large intervals of the primary reference temperatures and also at temperatures above the gold point. In the latter range these are - according to Henning and Moser (42) - the freezing points of copper (1358.03K), nickel (1728K), cobalt (1768K), palladium (1827K), platinum (2042K), rhodium (2236K), the melting point of alumina (2327K), the freezing point of iridium (2720K), and the melting points of niobium (2750K), molybdenum (2896K), and tungsten $(3695 \mathrm{~K})$.

A critical review of the chemical aspects of secondary melting point standards for the temperature range between 2300 and $3300 \mathrm{~K}$ was presented by Alcock (43). He pointed out that materials are needed whose melting points do not change within a wide range of oxygen partial pressure. Nietals appear not to be suited for this purpose (except in vacuum or in inert atmosphere) since some of them such as osmium, ruthenium, molybdenum and tungsten form rather volatile oxides, while others like titanium, zirconium or hafnium have their melting points affected by small amounts of oxygen. With refractory metal oxides considerably differing melting temperatures have been found depending on the kind of atmosphere and the laboratory performing the measurements (Ref. 44). For example, for the melting point of alumina in air values between 2298 and 2328K (according to IPTS-48) have been reported; finally a value of $2327 \pm 6 \mathrm{~K}$ was suggested by an IUPAC project team (Ref. 45). A critical survey of melting points of refractory oxides has recently been published (Ref. 46). Other problems may arise from the vapor pressures of the standard substances because of the condensation of material on the windows necessary for pyrometric temperature measurement and from the temperature-dependent absorption of radiation in the gas phase. For these and other reasons it is to be expected that the oxides of groups IIA, IIIA and IIIB are more suitable as temperature standards than those of higher groups; two of them, i.e. alumina $(2327 \mathrm{~K})$ and yttria $(2712 \mathrm{~K})$, are already being used for this purpose, one particular advantage being their low vapor pressure. Another possible candidate is lanthanum oxide (2584K) (Ref. 47). Promising materials for the use as secondary temperature standards are also eutectic mixtures between, for example, two binary oxide compounds; preferential vaporization of one oxide would not change the eutectic temperature as long as it did not completely disappear. Furthermore, a number of eutectic systems consisting of metal carbide and graphite or metal have recently been suggested as secondary temperature standards. Currently an IUPAC project team is engaged in the experimental determination of the exact eutectic temperatures of four such systems (Ref. 48).

Over a wide temperature range thermocouples are the most frequently used temperature measuring devices (Ref. 49). In a review the advantages and drawbacks of different thermocouple combinations for various temperature ranges were discussed by Guildner and Burns (50). Although the application of nickel-based thermocouples is usually restricted to rather low temperatures, Burley et al (51) described new alloys (Nichrosil and Nisil) which can be used up to about 1500K. The limit of applicability of the different platinumrhodium thermocouples is between about 1900 and $2100 \mathrm{~K}$ (Ref. 42, 50, 52). The maximum temperature for the most common type (Pt-Pt10\%Rh) is about 2050K; for Pt-Pt13\%Rh it is somewhat lower. The highest operating temperature is reported for the combination Pt $20 \% \mathrm{Rh}-\mathrm{Pt} 40 \% \mathrm{Rh}$ with about $2120 \mathrm{~K}$, but the thermo-emf is very low. The highest thermoelectric power is achieved with the Pt-Pt308Rh couple. For measurements in an oxidizing atmosphere up to $2500 \mathrm{~K}$ iridium-rhodium alloy thermocouples have been used (Ref. 50). However, they are expensive, have rather poor mechanical properties, relatively low thermoelectrical power, poor stability and short life. For very high temperatures (even above $3000 \mathrm{~K})$ different tungsten alloys have been used, the most common being the W3\% Re-W25\%Re thermocouple with the upper limit of $2573 \mathrm{~K}$ (Ref. 50) (the limit is given as $2773 \mathrm{~K}$ in Ref. 42). About $2800 \mathrm{~K}$ can be reached with the combination molybdenum-tantalum and about 3300K with a W-W50\%Mo thermocouple which has, however, a very low thermo-emf (Ref. 52). All these thermocouples can be employed only in hydrogen, in pure inert atmosphere, or in vacuum. Extended use of tungsten-rhenium couples in vacuum above $2200 \mathrm{~K}$ may change the emf substantially because of preferential evaporation of rhenium.

At temperatures above $1300 \mathrm{~K}$ the choice of insulating and sheathing materials becomes more and more important. Up to about $1800 \mathrm{~K}$ alumina may be used, although between 1500 and $1800 \mathrm{~K}$ beryllia is already the better insulator. Above $1800 \mathrm{~K}$ beryllia should be regarded as necessary but it does create 
problems because of its toxicity. Beryllia has a phase transformation at about $2320 \mathrm{~K}$ which sets an upper limit to its usefulness. Above $2300 \mathrm{~K}$ thoria is reported to be a suitable insulator for tungsten-rhenium couples but its slight radioactivity might be a problem. Metal sheaths must not act as oxygen getters because this may lead to the reduction of the insulating materials and subsequently to a contamination of the thermocouples. Noble metals may be employed for sheathing purposes but also tubes made of tantalum, niobium, W25\%Re, molybdenum and Mo25\%Re, which must be protected against oxidation.

At very high temperatures optical measurements with radiation pyrometers are the most reliable if not the only methods available. A very valuable check list when a pyrometer should be employed and which type is the best suited under given experimental conditions can be found in the review article by Kunz (53). Advantages of a pyrometer are measurements without physical contact and at a high speed, disadvantages are the problems connected with emissivity: the sample has to be a black body radiator or has to be in thermal equilibrium with one, or the emissivity of the sample has to be known. It should be noted that the emissivity of liquid alloys can change appreciably with composition (Ref. 54). Methods of compensating for emissivity variations or correcting for the effect of emissivity in pyrometry have been discussed by Ruffino (55). The effect of emissivity of real bodies on readings of pyrometers of all types has been extensively treated by Battuello and Ricolfi (56).

Pyrometry requires the measurement of radiation flux, using the eye to compare the unknown flux with that from a lamp of known characteristics (visual or subjective pyrometers) or a physical receiver for the same purpose (photoelectric or objective pyrometers). With respect to the radiation laws pyrometers can be classified as follows:

1. Spectral pyrometers which operate in such a narrow spectral range that an effective wavelength nearly independent of temperature can be assigned to them. Knowing the spectral emissivity the true temperature can be calculated. Since the measured radiation follows Planck's law, these pyrometers can be calibrated at a single fixed point.

2. Total radiation pyrometers respond spectrally over the entire effective spectral range of radiation emitted by the sample independent of the wavelength. The measured radiation obeys the Stefan-Boltzmann law, and the true temperature can be calculated from the total emissivity of the samples. 3. Spectral-band pyrometers operate in a broader spectral range so that at best only a strongly temperature-dependent effective wavelength can be assigned to them. Temperature corrections are only possible by numerical integration of the experimental emissivity curve.

4. Two-color (color or ratio) pyrometers are spectral or spectral-band pyrometers which make use of the ratio of the measured radiation in two different spectral ranges to determine the temperature. With narrow spectral ranges temperature corrections can be calculated from the ratio of the spectral emissivities at the two effective wavelengths.

According to Henning and Moser (42), the sensitivity of color pyrometers between 1300 and $4000 \mathrm{~K}$ is between 2 and $10 \mathrm{~K}$. If strong absorption of the emitted radiation is encountered, color pyrometers are superior to all other types. However, the assumption of equal target emittance at the two different wavelengths is very often not justified (Ref. 57). The various methods of two-color pyrometry were analyzed by Geda and snopko (58) and an optimal approach for the determination of the temperature suggested. The influence of different radiation fluxes from a hot surface with areas at different temperatures for a ratio pyrometer has been investigated mathematically and experimentally by Luhleich et al (59). With optimal experimental conditions the accuracy achievable with a standard pyrometer is $0.04 \mathrm{~K}$ at $1230 \mathrm{~K}$ and $2 \mathrm{~K}$ at $3800 \mathrm{~K}$ (Ref. 53). Obviously this accuracy will never be attained in normal phase diagram studies.

Instead of the human eye a physical receiver can be used to compare the radiation fluxes from sample and lamp, resp., thereby increasing the speed and the accuracy, and also extending the range to lower temperatures because of the infrared sensitivity. Such a photoelectric pyrometer was successfully used by Cezairliyan (18) for dynamic measurements of thermophysical properties at high temperatures. This spectral pyrometer allows 1200 measurements of the specimen temperature per second. Radiation fluxes from the sample and from a tungsten ribbon lamp of exactly limited time intervals are passed alternatingly through an interference filter into a photoamplifier, and during 
each time interval the signal of the photoamplifier is integrated and recorded. Another high speed pyrometer has been reported by Coslovi et al (60) who succeeded in making up to 13000 temperature measurements per second. Although the speed of this pyrometer is higher, ease of calibration and operation give definite advantages to the other instrument (Ref. 18) so that Kolesnichenko et al (61) designed a new high speed pyrometer for thermophysical measurements on the latter principle. High-speed pyrometry in laserpulse heating experiments at extreme rates of evaporation is the subject of an article by ohse et al (62). Under those conditions pyrometry was best applicable below 5000K, whereas above this temperature spectroscopic techniques were recommended. Also for laser-heated specimens sheindlin et al (37) developed a two-color pyrometer for temperatures between 2500 and $6000 \mathrm{~K}$ and high inert gas pressures. The signal strength had to be reduced and the width of the spectral range narrowed to keep the effective wavelength constant so that the calibration could be extrapolated to high temperatures. very accurate spectral pyrometer for laboratory use is the photon-counting instrument designed by Storms and Mueller (63) which can measure temperatures between 1400 and more than $2200 \mathrm{~K}$ to within 0.5 and $1.0 \mathrm{~K}$, resp., of IPTS-68. In most pyrometers the unknown radiation flux is compared with that of a lamp, and the accuracy depends on the characteristics of the lamp where especially the drift is a source of error. With the photon-counting pyrometer the radiation flux is measured directly, and for calibration only one fixed point (melting point of gold) and a variable but uncalibrated source of radiation are necessary.

\section{Thermal analysis}

The most important and most common methods for the investigation of phase diagrams are those usually summarized under the term "thermal analysis", especially heating or cooling-curve determinations and differential thermal analysis (DTA). A number of books exist on the application of these methods treating the subject from different points of view; see for example Garn (68), Blažek (69), Wendlandt (70), Wendlandt and Collins (71), and Heide (72). The most noticeable development in standard instrumentation within the last few years seems to be the growing automatization, i.e. the application of microcomputers and microprocessors and the availability of instruments with higher and higher upper temperature limits. Today commercial DTA-instruments can be obtained for temperatures up to $1850 \mathrm{~K}$ but there are quite a number of models which can be employed up to about $2700 \mathrm{~K}$. However, with increasing temperatures selection of the best crucible material becomes a crucial problem, especially if reactive substances or materials containing relatively volatile components are to be investigated. Although Smajic (73) reported the use of quartz crucibles up to nearly $1800 \mathrm{~K}$ for the investigation of high-alloyed steels, their safe limit of application seems to be rather lower (around $1500 \mathrm{~K})$. In most cases quartz is replaced by refractory oxides or metals for high-temperature measurements. Palenzona and coworkers, for example, employed molybdenum containers which had been sealed by arc welding for the investigation of the palladium-calcium (Ref. 74) and the thorium-tin system (Ref. 75) up to about $1700 \mathrm{~K}$. Additional problems with very high vapor pressures were encountered by Kaldis and coworkers in their phase diagram studies of rare earth-chalcogen systems (e.g. Ref. 76) using commercial DTA up to about 2500K. Specially developed tungsten crucibles made by electro-erosion were filled with the sample and sealed by electron bombardment using a special device to keep the main part of the crucible cool. Tantalum crucibles were employed by Abdusalyamova et al (77) in their investigation of the terbium-antimony system with commercial high-temperature DTA up to $2500 \mathrm{~K}$. cope with the high vapor pressure of antimony the crucibles were placed in larger tantalum containers sealed with a lid. A similar technique was used by Yatsenko et al (78) in their study of rare earth-indium phase diagrams up to about $1800 \mathrm{~K}$. Problems with crucible materials were encountered by Flukiger and coworkers in their investigations of binary vanadium- and nioium-systems with a commercial DTA-apparatus. Whereas for example in the vanadium-gold system alumina crucibles could be used for temperatures up to $2000 \mathrm{~K}$ (Ref. 79), these had to be replaced by beryllia in the systems vanadium-gallium (Ref. 80) (up to about 2000K) and niobium-gallium (Ref. 81) (up to about $2300 \mathrm{~K}$ ) since alumina caused a lowering of the melting points.

Practically all instruments for thermal analysis built for high temperature application employ optical methods of temperature measurement. Heetderks et al (82) have described a DTA-apparatus for measurements up to $3900 \mathrm{~K}$. The sample temperature is determined by an electronic pyrometer which measures the radiation from a cylindrical hole in the sample, and also serves for 
controlling the furnace temperature. The temperature difference is measured with one photodiode which receives by a chopper mechanism alternatingly the radiation from the sample and the reference material. This apparatus was used for the study of phase diagrams, mainly of transition metal carbides (Ref. 13, 14). Its accuracy seems to be of the order of $\pm 20 \mathrm{~K}$. During an investigation of the yttria-alumina system Caslavsky and Viechnicki (83) discovered well reproducible brightening and darkening phenomena during melting. Based on this effect they constructed a device for optical differential thermal analysis (ODTA) since a normal DTA was found unsuitable due to instability of the emf of the W3\%Re-W25\%Re thermocouples. With this apparatus the temperature difference curve is obtained by taking the difference between the signals of two optical pyrometers, one measuring the temperature of the blackbody enclosure which contains the sample and also serves as a reference, and the other measuring the temperature of the sample itself. With this instrument, the alumina-yttria phase diagram was investigated with a reproducibility of the melting points of $\pm 7 \mathrm{~K}$ between 1500 and $2500 \mathrm{~K}$. A high-temperature DTA for measurements between 1200 and $3400 \mathrm{~K}$ was described by Knotek et al (84). Two color pyrometers determine the temperatures of sample and reference and a voltage-difference amplifier smoothes and compares the output signals of the two pyrometers and thus generates a difference signal. Based on the determination of the melting points of five pure metals between 1683K (silicon) and $2133 \mathrm{~K}$ (chromium) an accuracy between 4 and $8 \mathrm{~K}$ was claimed in this temperature range.

Within the last twenty years a number of methods have been developed for the investigation of levitated samples at high temperatures. The most common approach up to now is levitation of an electrically conducting (mostly metallic) sample in an inhomogeneous magnetic field in combination with induction heating. Thus it became possible to investigate solid and liquid materials - also very reactive ones - avoiding direct contact with any crucible material. A direct application of electromagnetic levitation to phase diagram investigation was reported by Jorda et al $(85,86)$. During a study of the niobium-germanium system with a conventional DTA-apparatus it turned out that niobium-rich samples would react with all crucible materials. Therefore a procedure was developed to determine heating curves of levitated samples. The apparatus could be used up to about $3300 \mathrm{~K}$ at heating rates up to $50 \mathrm{Kmin}^{-1}$; evaporation of the samples was greatly reduced by applying an argon-pressure of up to 4 bar. The temperature was measured with a two-color pyrometer standardized by comparison with a W3\%Re-W25\%Re thermocouple. An interesting, somewhat different levitation method originally developed for the Spacelab program was presented by Lukas and Hemminger (87) whereby the sample is kept in the desired position by an ultrasonic field. Lee and Fent (88) described an acoustic levitation apparatus for submillimeter size samples. A third approach for levitating solid and liquid materials is based on aerodynamic principles. It has been combined with different heating methods: Oran and Berge (89) described an aerodynamic levitation system for bulk samples of $2-3 \mathrm{~mm}$ diameter in combination with an elliptical imaging furnace; Nordine and Atkins (90) reported the aerodynamic levitation of laser-heated (up to 2300K) solids of comparable size in gas jets; and Ouiada and Badie (91) presented an aerodynamic levitation apparatus coupled with a solar furnace for the investigation of liquid samples of about $4 \mathrm{~mm}$ size.

A review of methods of simultaneous DTA and high temperature thermomicroscopy was given by Schultze (92) distinguishing two possible arrangements: unconventional microscopes in combination with "classical" heater systerns and unconventional sample holder assemblies with "classical" microscopes. The investigation of the melting behavior of different phosphate systems up to $1550 \mathrm{~K}$ was given as an example of the applicability of this technique (Ref. $93,94)$.

\section{Other methods}

Thermosonimetry is a technique where the sound emitted by a substance is measured as a function of temperature while the substance is subjected to a controlled temperature program. Clark (95) described an apparatus where the acoustic signal is transmitted by a waveguide to the detector system which consists of a piezoelectric transducer crystal. Either the rate or the amplitude (energy) or the frequency can be measured as a function of temperature. In a second paper Clark and Garlick (96) compared DTA and thermosonimetric measurements of different NBS - ICTA standards up to about 1300K; however, the method should also be applicable at higher temperatures. Another acoustic technique is thermoacoustimetry which is based on the temperature 
dependence of the elastic properties - and thus also of the velocity of sound - in a material. LQnvik (97), for example, used this technique to investigate the alpha-beta transformation of quartz.

Dilatometers are frequently used for the investigation of phase diagrams, since phase transitions can often be identified by a change of the temperature aependency of the expansion coefficient (thermodilatometry). A special counterbalanced pushrod vacuum dilatometer for low-strength materials was presented by Rose (98) and was tested with in iron-standard up to 1470K. The measurement of magnetic properties as a function of temperature (thermomagnetometry) frequently yields valuable information, and many magnetic transitions, though occurring mostly at rather low temperatures, can be detected only by this method. It can be applied up to very high temperatures as shown by Mủller and Güntherodt (99) who developed a pendulum balance for magnetic susceptibility measurements up to nearly 2000K. Schlawne et al (100) enployed magnetic measurements to determine very accurately the liquidus line of gold-cobalt alloys. A simplified apparatus for detecting solid state transformations in a steel sample by a.c. induction up to about $1500 \mathrm{~K}$ was presented by Valenzuela and Miller (101). The detection is based on the changes in magnetic permeability and/or electric resistivity accompanying the solid state reaction. The determination of a phase transition by electroconductometric analysis was reported by Roitti(102).

One group of techniques attempts a separation of the phases present at a certain temperature to determine their composition independently. This even led to the construction of high-temperature centrifuges (Ref. 103, 104) for the determination of melting intervals. A different approach aims at a controlled solidification of a molten sample leading to a characteristic sequence of phases. Shindo (105) reported results of a study of the magnesiatitania system using the so-called "Slow Cooling Float Zone Method". A rodshaped sample is melted locally in the middle, and during cooling its two ends are pulled apart under rotation in opposite directions. The different zones which form during the crystallization process are analyzed by electron microprobe. The phases in a system in the correct sequence can be obtained by the diffusion couple technique in which the pure starting materials are allowed to diffuse into each other at a well defined temperature. The resulting specimens can be investigated by microanalytical methods or they can be sectioned and the invididual pieces analyzed separately. This method is not limited to binary systems, as was shown e.g. by the investigation of the molybdenum-silicon-carbon system by van Loo et al (106).

Very accurate phase boundaries are frequently obtained from thermodynamic measurements, especially if partial molar properties are determined at a certain temperature as a function of composition. These may be partial molar enthalpies from calorimetric measurements (e.g. Ref. 107, 108) or partial molar Gibbs energies from emf or vapor pressure measurements. In one special isopiestic technique, where a number of samples are equilibrated in a temperature gradient with the vapor of the volatile component from a reservoir, phase boundaries within a certain temperature interval can be determined directly from the so-called equilibrium curves (e.g. Ref. 109, 110). As an example of an electrochemical method the work by Weppner et al (111) will be mentioned. In the same galvanic cell the concentration of one component is changed by coulometric titration and the thermodynamic activity is determined by the emf. With a small number of samples a wide range of composition can be covered, and Weppner et al (112) investigated the ternary copper-germaniumoxygen system between 1023 and 1223K. Recently Tran et al (113) determined phase boundaries at certain temperatures up to $1100 \mathrm{~K}$ using "reduction thermogravimetry". Distinct changes in the slope of the weight loss versus time curve were taken as evidence for the phase boundaries.

\section{THERMODYNAMIC PROPERTIES: EXPERIMENTAL METHODS}

The ultimate goal of the thermodynamic investigation of a system is the determination of all partial and integral quantities as a function of concentration, temperature and pressure in agreement with the phase diagram. Obviously various methods of differing accuracy are necessary so that the complete thermodynamic elucidation of a system is frequently the work of several research groups whose results have to be critically evaluated. Such compilations and evaluations have been carried out especially by Hultgren et al (114) and by Kubaschewski (e.g. Ref. 115). As in previous publications (Ref. 3-5) calorimetric, electromotive force and vapor pressure techniques will be discussed. 


\section{Calorimetric methods}

The general principles of calorimetry have been described by Hemminger and Höhne (116). Since for a high temperature chemist both thermophysical and thermochemical data are important, the calorimetry of both non-reacting and reacting systems will be treated. Several review articles on high-temperature reaction calorimetry have appeared in recent years. Navrotsky (117) has treated the calorimetry of oxides more from the point of geology using molten oxide solvents. Kleppa (118) concentrated on the use of heat flow calorimeters both in oxidic and metallic systems, and Kubaschewski (119) and Predel and Arpshofen (120) reviewed calorimetric methods in metallurgy.

In high temperature work many scientists now seem to favor Calvet-type twin calorimeters elsewhere described (Ref. 3). A summary of the application of such calorimeters to metallurgical problems was given by Zahra and Laffitte (121). With a manganese-nickel solvent Kleppa and Kong (122) determined the transformation enthalpy of diamond-to-graphite and the heat of formation of $\mathrm{Mn}_{5} \mathrm{C}_{2}$ at $1320 \mathrm{~K}$. Similarly with a ternary manganese-nickel-boron solvent the two authors (Ref. 123) measured the enthalpy of formation of $B$. The Calvet calorimeter has also been used to determine partial molar enthalpies of oxygen in metal-oxygen systems by Gerdanian and coworkers (e.g. 124, 125). Niore recently Kleppa and coworkers have applied this method to metal-hydrogen systems (e.g. Ref. 126-130). They replaced the furnace of a Sieverts apparatus by a Calvet-type calorimeter and could determine simultaneously both the partial molar free enthalpy and the partial molar enthalpy of hydrogen. By using a new integrator based on a voltage-to-frequency converter combined with a digital system interfaced to a microcomputer kleppa et al (131) could improve the precision of the Calvet-type calorimetric measurements to the order of $\pm 0.1 \%$ at $924 \mathrm{~K}$. Recently a new sensitive heat flow calorimeter to determine partial molar enthalpies of hyärogen or oxygen in metals and alloys up to $1100 \mathrm{~K}$ has been described (Ref. 132). The data are recorded by a microprocessor computer integrator including timer and printer, the calorimeter can detect heat effects of $0.06 \mathrm{~J}$, and is suitable for precise measurements of $1 \mathrm{~J}$ or more. For the determination of the enthalpy of mixing up to $1750 \mathrm{~K}$ a heat-flow calorimeter is commercially available with experimental and reference crucibles arranged one on top of the other surrounded by the crown of thermocouples of the calorimetric detector (Ref. 133). The sensitivity of the calorimeter depends on the mass of the sample, i.e. on the filling height of the crucible and the type of the calibrating technique, and improvements have been suggested to obtain reproducible results (Ref. 134). The design of different calorimetric detectors, the mixing method with a stirring device to avoid parasitic thermal effects, and the automatic acquisition and treatment of the data for such a high-temperature calorimeter have been described in detail (Ref. 135).

Accurate measurements of both the enthalpy of mixing and the differential change of the enthalpy of mixing with composition at temperatures up to $1300 \mathrm{~K}$ can be carried out by a calorimeter developed by Oehme and Predel (136). An isoperibol calorimeter with a very similar arrangement of crucibles was used by Predel and Gerdes (137) to determine the enthalpy of mixing of alloy systems. The temperature difference between the sample and the surrounding calorimeter block was measured as a function of time, and the enthalpy of mixing obtained from the temperature difference-time curves by calibration. A simple DTA-calorimeter (called "Tandem" calorimeter) to determine enthalpies of formation and transformations between 800 and $1600 \mathrm{~K}$ within $5 \%$ has been constructed by Hoster and Kubashewski (138). The temperature difference between specimen and reference specimen is plotted as a function of time and the temperature difference-time curve duplicated as closely as possible by electricaliy heating the reference specimen.

The adiabatic calorimeter of Dench and Kubashewski (139) has been further improved by Kubashewski and Grundmann (140) by redesigning the measurement and control equipment. The calorimeter operates between 773 and $1823 \mathrm{~K}$ with an accuracy of better than 1\% for heat capacity measurements, a reliability of the enthalpies of formation within $400 \mathrm{~J} / \mathrm{mol}$, and of enthalpies of transformation within $100 \mathrm{~J} / \mathrm{mol}$. Lück and Predel (141) have constructed a solution calorimeter for temperatures up to $1873 \mathrm{~K}$. In principle it is like a quantitative DTA apparatus presumably with an accuracy of $\pm 5 \%$ as stated for a similar calorimeter (Ref. 142). A significant advance towards higher reaction temperatures was made possible by levitation calorimetry. Frohberg and Betz (143) have described an apparatus which allows the determination of the enthalpy of mixing and partial molar enthalpies up to and - in principle - above $3300 \mathrm{~K}$ by magnetic levitation. The larger pure sample is melted, the smaller 
added, solid or liquid, in the magnetic coil, and the temperature change caused by the alloying reaction measured by a two-color pyrometer. Measurements can be carried out either with a constant final temperature or with a constant heating rate, and the enthalpy effects are calculated from the temperature difference-time curves using the heat capacity of the pure metals.

Calorimetry of non-reacting systems is aiming at the determination of heat capacities and enthalpies of transformation. Usually heat capacity measurements below room temperature are made by adiabatic calorimetry while above room temperature drop calorimetry or dynamic adiabatic calorimetry is mostly employed. Due to the differences in techniques it is not surprising that frequently inconsistencies are observed between low- and high-temperature heat capacity data. A method which bridges the gap is laser-flash calorimetry for precise and accurate measurements between 80 and 1100K (Ref. 144). A thin disc-shaped sample covered by an absorbing plate of glassy carbon is resistance heated to the desired temperature, then further heated a temperature increment by a pulse of a ruby laser, and the energy absorbed, the temperature and the temperature increment are measured. After correcting for heat losses the heat capacity is determined from the energy input using a sapphire disc as a calibrating substance. The method is applicable to metallic and insulating materials, and its overall inaccuracy is estimated to be $\pm 1.0 \%$ at $800 \mathrm{~K}$.

Shpilrain et al (145) described a pulse-differential method to measure heat capacities of solid and liquid metals up to $1800 \mathrm{~K}$ and 300 bar which they improved to conduct experiments up to $3000 \mathrm{~K}$ and 300 bar (Ref. 146). The pulsedifferential method is based on a comparison of the heating or cooling rate of a sample with the corresponding rate for a sample of known heat capacity. With a high-density current Shaner et al (147) have measured the heat capacity of liquid tantalum and molybdenum under high gas pressure. For extreme conditions ( $T$ 12000K, p 4 kbar) Seydel et al (20), developed a submicrosecond pulse-heating method with heating rates of $10^{9} \mathrm{Ks}^{-1}$. A wire-shaped sample is resistance heated in a pressure cell filled with water, and current, voltage, thermal expansion and temperature are simultaneously measured. With a fast two-color pyrometer the temperature is determined from the ratio of the light intensities at the unknown temperature and the melting temperature assuming an emissivity constant with temperature. For the measurement of heat capacities of semiconducting materials up to $1500 \mathrm{~K}$ Naito et al (148) have developed a direct pulse-heating calorimeter in which the sample rod is surrounded by a cylindrical adiabatic shield made of molybdenum. Electrical energy is supplied simultaneously to sample and shield so that the temperature rise for both is the same. Sources of errors are carefully analyzed, and the heat capacities of graphite and SiC were measured between 300 and $1270 \mathrm{~K}$ with an imprecision of less than $0.5 \%$

The most accurate measurements of heat capacities are obtained by adiabatic calorimetry. For intermediate temperatures (70-700K) Inaba (149) constructed a Pt-10\%Rh vacuum calorimeter with an accuracy of better than $0.2 \%$ when tested with a standard reference sample of synthetic sapphire. Cash et al (150) converted their calorimeter (300-1300K) from manual data acquisition and analog temperature control of the adiabatic shields to digital computer operation. The error in the heat capacity could be kept within the value obtained by the manual method $( \pm 0.7 \%)$. For the measurements of heat capacities of solid and liquid metals in the temperature range 800-1800K Roget and LeCoze (151) constructed an adiabatic calorimeter based on a model previously developed by Braun and Kohlhaas (152). As an important improvement they introduced automatic control of the heating of the adiabatic shield. The levitation apparatus of Betz and Frohberg (143) has been used in combination with an isoperibol copper block calorimeter to determine enthalpy contents of molybdenum (Ref. 153) and niobium (Ref. 154) between 2082-3383K, and 20313159K, resp., by drop calorimetry.

More and more frequently differential scanning calorimeters (DSC) are used to measure heat capacities and enthalpies of transformation since several types are now commercially available. A DSC can be described as a dynamic twin calorimeter using a reference and a sample cell. The temperature aifference between the two cells is either kept constant by adding electrical energy (power compensated DSC), or the temperature difference is measured (heat flux DSC). In principle, differential scanning calorimetry should be a quick and fairly accurate method to determine heat capacities, but in actuality careful calibration and painstaking experimentation are required, especially for liquid alloys (Ref. 155). The accuracy of the heat capacity of solid pyrite 
$\left(\mathrm{FeS}_{2}\right)$ measured by DSC between 100 and $800 \mathrm{~K}$ was stated to be about $1 \%$ over most of the temperature range and within $2 \%$ at the very lowest and highest temperatures (Ref. 156) as compared to data by precision adiabatic calorimetry. A DSC based on the Calvet heat-flow principle operating in the temperature range from 150 to $1100 \mathrm{~K}$ at pressures up to and above 100 bar has been described (Ref. 157). Heat capacities can be determined by stepwise scanning and several applications are shown.

\section{EMF Methods}

Both liquid and solid electrolytes are frequently used to determine thermodynamic quantities. An extensive discussion of the emf technique with fused salt electrolytes was given by Moser (158). No really novel techniques with liquid electrolytes have been reported, but as an example of an application of interest in steel making the experiments by Kay (159) should be mentioned. oxygen concentration cells with molten ionic slags were employed to determine the thermodynamics of oxide formation from oxygen and metals dissolved in iron in the temperature range 1773-1873K. More and more solid electrolytes are used, and the reliability of such emf cells has increased considerably. Various aspects of electrolytes are treated in a book edited by Geller (160). Solid electrolytes and their applications are described in a book edited by Subbarao (161), i.e. thermodynamic and kinetic studies, oxygen probes and pumps, fuel cells, high energy density batteries, and solid state ionics. The most frequently employed solid electrolyte is oxygen ion conducting stabilized zirconia. It is used not only in alloy thernodynamics but also as gas sensor, component in fuel cells, oxygen pump and oxygen recycler in closed systems, as oxygen gauge, esp. in steel making, for analysis of exhaust gases, and for tuning of combustion processes.

A very careful collaborative study of commercially available calcia- and yttria-stablized zirconia tubes as oxygen gauges was carried out by IUPAC Commission II.3 (Ref. 162). The performance of such gauges between pure oxygen and air as reference gas was studied by various laboratories and fundamental principles, preparation and experimental procedure were discussed. As the principal sources of error the following factors were pointed out: 1) Physical permeability of the ceramic materials due to microcracks or open porosity. Because of poor thermal shock resistance zirconia-tubes should not be cooled faster than $150 \mathrm{~K} / \mathrm{h}$. 2) Uncertainty in cell temperature, cell voltage, and evaluation of the reference partial pressure of oxygen. 3) Nonuniform cell temperature causing thermoelectric voltage and uncertainty in the cell temperature. 4) Small electronic contribution. The flow of electrons is counterbalanced by a small ionic current which induces electrochemical permeability of the material to oxygen. This will inject gas in the gas stream with the smaller partial pressure of oxygen, but the diffusive process may also polarize the measuring electrode, and the measured voltage is lowered by the electrode overpotential. Since zirconia-cells behave as moderate to high impedance voltage sources, the voltage delivered must be measured with a voltmeter of high internal impedance; gauge and external leads have to be shielded to reduce electrical (capacitance) pick-up. With a carefully constructed gauge the compounded error was less than $0.3 \%$. When measurements at much lower partial pressure of oxygen are made, electronic contributions may play a significant role, and problems in design are greatly increased. Other reference electrodes have to be used which might lead to the formation of reaction layers at the electrolyte surface. More importantly a considerable uncertainty might be introduced due to lack of standardization of the free energy of formation of the reference electrode reaction (Ref. 163). The effect of pressure on the emf of some solid-state reference electrodes has been studied by Jacob and Iwase (164).

Numerous investigations of thermodynamic properties of oxygen dissolved in liquid metals have been reported. Alcock (165) reviewed the liquid metaloxygen probe, described the general experimental set-up, and discussed the work done up to date both in the laboratory and on a pilot plant scale. The physico-chemical properties of solid oxide electrolytes at steel making temperatures with respect to high melting points, high thermodynamic stability, and low vapor pressure were discussed by Janke and Fischer (166). Janke and Schwerdtfeger (167) developed a new rod-sensor with a stabilized zirconia- or thoria-electrolyte and metal-metal oxide reference mixture for short-time measurements of oxygen in steel melts at $1873 \mathrm{~K}$. Possible sources of error in the application of solid oxide electrolytes for the determination of low oxygen activities in steel melts were treated by Janke and Richter (168). A solid electrolyte sensor for steel making slags of the basic oxygen converter was developed by Kawakami et al (169). Recently Janke (170) described oxygen 
probes based on calcia-doped hafnia or calcium zirconate for use in metallic melts. Worrell (171) has developed a sulfur-doped stabilized zirconia electrolyte as sulfur-sensor in steel melts. Activities of liquid alloys are usually determined with a solid electrolyte cell by measuring the oxygen potential of the alloy saturated with the oxide of the more electropositive element. Problems might arise with finding a non-reacting container for the oxide and with the solubility of oxygen in the melt at relatively high oxygen potentials. Jacob (172) has proposed three-phase equilibria to overcome these difficulties which he used for the determination of manganese activities in liquid cobalt-manganese alloys (Ref. 173). Alcock et al (174) devised an interesting method for the direct measurement of the partial molar entropy of oxygen in a single phase or multiphase mixture by an "entropy meter" consisting of a non-isothermal solid electrolyte twin cell.

In the past fifteen years beta-alumina (Ref. 160) has played an increasingly important role as superionic conductor. As examples of the application to alloy thermodynamics the determination of sodium activities in liquid sodiumtin (Ref. 175), gallium-sodium (Ref. 176), sodium-thallium (Ref. 177), and of the pressure effect on the concentration fluctuations (up to 1100 bar at 900K) in gallium-sodium (Ref. 178) will be mentioned. Replacing sodium by silver gave an electrolyte which allowed the measurement of activities of silver in silver-gold alloys (Ref. 179). Similarly copper-beta-alumina was successfully used to determine copper activities in liquid copper-tin alloys (Ref. 180). Farrington and Dunn (181) succeeded in replacing the $\mathrm{Na}^{+}$content of beta"alumina by a variety of divalent cations to prepare high conductors. Recently even trivalent solid electrolytes could be obtained from beta"-alumina by ion exchange reactions (Ref. 182).

Calcium fluoride has been used as a solid electrolyte to measure fluoride chemical potentials and activities in alloys for quite some time. Problems encountered, especially the effect of oxygen on the electrolyte, and results obtained are discussed by Kleycamp (163) who investigated a considerable number of transition metal systems by this technique. Coulometric titrations on several liquid calcium and barium binary alloys were carried out by Delcet et al (184) with calcium and barium fluoride solid electrolytes. Solid solutions of barium fluoride-barium carbide were also studied as a carbide electrolyte (Ref. 185), and calcium fluoride electrolytes have been employed for some time as sulfur sensors (Ref. 187). Using one metal, its sulfide, and calcium sulfide as the other electrode, free energies of formation of several sulfides were measured with a calcium fluoride electrolyte (Ref. 187). For the measurement of sulfur potentials in oxidizing environments between 773 and $1123 \mathrm{~K}$ calcium fluoride saturated with calcium sulfide, thoria doped with calcia and calcium sulfide, and calcium sulfide-yttrium sulfide were suggested (Ref. 188).

\section{Vapor pressure methods}

For vapor pressure measurements in the low pressure molecular flow region the effusion method in its several variants has been dominant in the study of equilibria and vapor pressures at high temperatures. For those interested in this method a study of the NBS Spec. Publ. 561 (Ref. 189) is highly recommended. Especially the articles by Cater (190) on the current state of effusion method and techniques and by chatillon et al (191) on interactions between Knudsen cells and the systems investigated contain valuable information on all the variants of and problems associated with the effusion method. An effusion experiment is based on several assumptions which might not always be fulfilled. The assumptions are: 1) The cell is isothermal and the temperature known as accurately as possible. 2) The cell is in thermodynamic equilibrium, i.e. it is in thermal and chemical equilibrium and there is no pressure gradient. Temperature gradients cause mass transport effects and should be eliminated. However, the effusion orifice may be obstructed if the temperature of the orifice is lower than that of the sample. Heating by radiation is preferred, and heat pipe envelopes are most effective in reducing thermal gradients. Chemical equilibrium is maintained if the evaporation coefficient is unity, and the condensed phase is in equilibrium with each vapor species. 3) The cell is assumed to be inert, i.e. the only interactions with the walls are random reflections, and grain boundary or surface diffusion, diffusion into or through the wall, bulk surface flow (creeping), and chemical reactions with the cell are absent. 4) The orifice is ideal (zero thickness) or the geometry is well known and clausing factors are available. 5) Pressures are in the molecular flow region. 
Real cells deviate from equilibrium, due to the open orifice a pressure gradient is established yet the isotropy condition is assumed. Effects of cell geometry and vaporization coefficients have been extensively studied, and correction factors are available. Surface diffusion will enhance the measured pressure, especially with ideal orifices. Bulk surface flow (creeping) - a problem with liquid samples - can be reduced by using single crystal cells, sharp edged cups, or selecting cell material that is not wet by the sample. Creeping was so serious with liquid ternary oxide melts at $1960 \mathrm{~K}$ that cells had to be made out of solid molybdenum and could not be reused even after careful cleaning (Ref. 192). Surface depletion on the other hand is much more of a problem with solid samples. Tendency towards surface depletion increases with temperature, and it can be reduced by using a large sample surface and by keeping the change in composition small. Preliminary thermodynamic calculations will help in choosing the best cell material.

The best known effusion techniques are mass loss and collection methods, recoil momentum techniques, and Knudsen cell mass spectrometry. Simple weighing of the cell before and after effusion is the least precise, and the use of vacuum balances is much preferred. Even better is a collection technique. If the collecting angle is only a few degrees, clausing and other corrections are not necessary. However, very sensitive analytical techniques like radiochemical counting, neutron activation, microprobe, electrochemical, or spectrophotometric analysis are required. A variant with a twin cell was suggested by Peltner and Herzig (193) for a direct determination of activities. One cell is loaded with the alloy, the other with the pure component, each with a different radioactive isotope. The effusate is collected and the amounts of the component determined by counting the rates of decay of the two radioisotopes. The most important recoil momentum technique is torsion effusion (TORKER) which when the cell is suspended from a microbalance will also allow the absolute measurement of the mean molecular weight of the vapor. With proper precautions the method is reliable, and will give reproducible results. Instead of wires flat Pt-10\% Ni ribbons are now frequently used for suspension since ribbons are more uniform and their torsion constants more permanent. In a torsion experiment either the angle of torsion is measured or the torsion is magnetically compensated. A new development is the dynamic or oscillating torsion effusion cell (Ref. 194). The torsion effusion pendulum is suspended from the arm of a vacuum semimicrobalance for simultaneous Knudsen effusion measurements. The pendulum is operated in the dynamic mode, the swing is alternately enhanced and retarded by the momentum of the effusing vapor and the pressure is derived from the equation of motion. Data acquisition is automated by a video or a computer method. The computer method (Ref. 195) involved reflecting low-power laser beams from mirrors attached to the pendulum and detection of the reflected beams by photodetectors interfaced to a laboratory computer (Ref. 190). The advantages are the smoothing out of various experimental residual torques by the oscillation and easy automation for data acquisition.

The Knudsen cell mass spectrometry made its first appearance in the early fifties with magnetic deflection instruments. In 1958/59 the cheaper timeof-flight mass spectrometers became available, and now more and more the still less expensive smaller quadrupole units are used. The magnetic instruments have a higher resolving power but the change of mass is slower; the quadrupole mass spectrometers are cheaper and smaller, the change of mass is more rapid but the sensitivity changes with mass, and the resolving power comes in different ranges. The techniques have changed little and the two most fundamental problems are still fragmentation, i.e. the identification of parent species from which the observed ions are derived, and the determination of sensitivity constants to get absolute partial pressures (the cross section problem). Fragmentation is of minor or no importance in alloy thermodynamics, and for activity measurements the determination of sensitivity constants can be simplified or eliminated by using multiple Knudsen cells or by determining the ion current ratios of the two components. The application of multiple cells (differential mass spectrometry) to liquid oxide thermodynamics has been carefully studied and described by Allibert and Chatillon (197). If the partial pressures of the alloy compcnents do not differ by more than two orders of magnitude the thermodynamic properties of the alloy can be obtained by measuring the ion current ratios of the two components, and again the sensitivity constants are eliminated (Ref. 198, 199). The sensitivity problem has been treated in some detail by cater (190), and various aspects of high temperature mass spectrometry, especially parasitic phenomena by chatillon et al (191). Use of radiation rather than electron bombardment heating is recommended, and attention should be paid to thermal 
leakage along thermocouple wires and the thermocouple junction. Improvements in the past years were mainly due to refinement of technique, improved mechanical stability of the effusion source, a careful analysis of parasitic reactions, and automated data acquisition and treatment. Parisitic contributions may be due to evaporation from surfaces around the orifice and from deposits in the ion source, from residual gases, and from parasitic ions coming from the furnace. The parasitic flow can be trapped by a set of hot collimators which react chemically with the gases or by perfectly aligned cold collimators so that the ion source can only view the inside of the cell through the orifice (Ref. 191). A control and data acquisition system for a high temperature Knudsen cell quadrupole mass spectrometer was described by Liu and Muenow (200). The effusate is directed through a movable shutterplate into the ion source of a low resolution quadrupole mass filter which is interfaced to an on-line minicomputer. The application of a Knudsen cell quadrupole mass filter to the determination of the activities of copper-tin melts was discussed by Paulaitis and Eckert (201). The series "Advances in Mass spectrometry" and the Mass spectrometry Bulletin should be consulted for further developments in Knudsen cell mass spectrometry.

\section{REFERENCES}

1. H. Ipser and K. L. Komarek, Z. Metallkd. 75, 11-22 (1984).

2. K. L. Komarek, in Metallurgical Chemistry, ed. O. Kubaschewski, HMSO, London, I. 6, 75-95 (1972).

3. K. L. Komarek, Z. Metallkd. 64, 325-341, 406-418 (1973).

4. K. L. Komarek, Ber. Bunsenges. Phys. Chem. 81, 936-949 (1977).

5. K. L. Komarek, Ber. Bunsenges. Phys. Chem. $87,709-717$ (1983).

6. L. Kaufman and H. Bernstein, Computer Calculation of Phase Diagrams, Academic Press, New York (1970).

7. I. Ansara, Internat. Metals Rev. 24, 20-53 (1979)

8. M. Hansen and K. Anderko, Constitution of Binary Alloys, McGraw-Hill, New York (1958).

9. R. P. Elliott, Constitution of Binary Alloys, First Supplement, McGraw-Hill, New York (1965).

10. F. A. Shunk, Constitution of Binary Alloys, Second Supplement, McGraw-Hill, New York (1969).

11. W. G. Moffatt, The Handbook of Binary Phase Diagrams, General Electric Co., Schenectady (current and ongoing).

12. E. Rudy and J. Progulski, Planseeber. Pulvermet. 15, 13-45 (1967).

13. E. Rudy, J. Less-Common Met. 33, 245-273 (1973).

14. P. Rogl, S. K. Naik and E. Rudy, Monatsh. Chem. 108, 1189-1234 (1977).

15. L. F. Vereshchagin and N. S. Fateeva, High Temp.-High Press. 9, 619-628 (1977).

16. S. V. Popova and L. N. Fomicheva, J. Less-Common Met. 77, 137-140 (1981).

17. A. Cezairliyan, M. S. Morse, H. A. Berman and C. W. Beckett, J. Res. Nat. Bur. Stand. 74A, 65-92 (1970).

18. A. Cezairliyan, High Temp. Sci. 13, 117-133 (1980).

19. J. W. Shaner, G. R. Gathers and C.'Minichino, High Temp.-High Press. 8, $425-429$ (1976).

20. U. Seydel, H. Bauhof, W. Fucke and H. Wadle, High Temp.-High Press. 11, 35-42 (1979) .

21. A. Cezairliyan and J. L. McClure, High Temp.-High Press. $8,461-467$ (1976).

22. A. P. Miller and A. Cezairliyan, Int. J. Thermophys. $2,63-70$ (1981).

23. J. Coutures, F. Sibiende, A. Rouanet, M. Foex, A. Revcolevski and R. Collongues, Rev. Int. Hautes Tempér. Réfract. 11, 263-269 (1974).

24. M. Yoshimura, F. Sibiende, A. Rouanet and M. Foex, J. Solid State Chem. 16, 219-232 (1976).

25. D. Suresh, P. K. Rohatgi and J. P. Coutures, Solar Energy 26, 377-390 (1981).

26. M. Mizuno, T. Yamada, A. Taguchi and M. Machida, Yogyo Kyokai Shi 89, 488-494 (1981).

27. H. W. Newkirk and B. B. Brenden, J. Amer. Ceram. Soc. 43, 146-150 (1960).

28. A. Kishi, K. Takaoka and M. Ichihashi, Thermal Analysis, Proc. 5th ICTA, ed. H. Chihara, Heyden, London 554-557 (1977).

29. A. Maesono, M. Ichihashi, K. Takaoka and A. Kishi, Thermal Analysis, Proc. 6th ICTA, ed. H. G. Wiedemann, Birkhauser, Basel, 1, 195-200 (1980).

30. A. Maesono, M. Ichihashi, A. Kishi, K. Takaoka, Z. Hara and K. Akechi, ibid. 1, 219224 (1980).

31. W.-D. Emmerich, E. Kaisersberger and H. Pfaffenberger, Thermal Analysis, Proc. 7 th ICTA, ed. B. Miller, Wiley, Chichester, 1 , 163-168 (1982).

32. R. W. Ohse, J. F. Babelot, G. D. Brumme and P. R. Kinsman, Ber. Bunsenges. Phys. Chem. 80, 780-786 (1976).

33. R. W. Ohse and P. R. Kinsman, High Temp.-High Press. 8 , 209-215 (1976).

34. R. W. Ohse, J. F. Babelot, A. Frezzotti, K. A. Long and J. Magill, High Temp. -High Press. 12, 537-548 (1980).

35. C. Nordine, E. H. Lee and J. I. Hurd, Rev. Int. Hautes Tempér. Réfract. 17, 165-171 (1980). 
36. A. V. Kirillin and M. A. Sheindlin, Teplofiz. Vysok. Temp. 18, 966-973 (1980); High Temp. 18, 733-738 (1980).

37. M. A. Sheindlin, V. A. Kirillin, L. M. Kheifets and K. A. Khodakov, Teplofiz. Vysok. Temp. 19, 839-848 (1981); High Temp. 19, 620-627 (1981).

38. I. C. Finlay and D. B. Green, J. Phys. E 9, 1026-1035 (1976).

39. K. Baumüller, M. Haschke and K. Schmidt, Technik 33, 222-224 (1978).

40. C. Bassani, C. A. Busse and F. Geiger, High Temp.-High Press. 12, 351-356 (1980).

41. U. Schley, Thermochim. Acta 40, 73-91 (1980).

42. F. Henning and H. Moser, Temperaturmessung, Springer, Berlin (1977).

43. C. B. Alcock, High Temp.-High Press. 11, 241-249 (1979).

44. S. J. Schneider, Nat. Bur. Stand. (U. S.) Monogr. 68, 31 pp (1963).

45. S. J. Schneider, Pure Appl. Chem. 21, 117-122 (1979).

46. J. Hlavač, Pure Appl. Chem. 54, 681-688 (1982).

47. J. P. Coutures, Pure Appl. Chem., to be published.

48. K. L. Komarek, IUPAC Commission II.3.

49. R. P. Hudson, Rev. Sci. Instrum. 51, 871-881 (1980).

50. L. A. Guildner and G. W. Burns, High Temp.-High Press. 11, 173-192 (1979).

51. N. A. Burley, R. M. Hess and C. F. Howie, High Temp.-High Press. 12, 403-410 (1980).

52. F. X. Eder, Arbeitsmethoden der Thermodynamik, Springer, Berlin (1981).

53. H. Kunz, High Temp.-High Press. 11, 193-208 (1979).

54. W. Dokko and R. B. Bautista, Met. Trans. 11B, 309-312 (1980).

55. G. Ruffino, High Temp.-High Press. 11, 209-220 (1979).

56. M. Battuello and T. Ricolfi, High Temp.-High Press. 12, 247-252 (1980).

57. M. Pasta, G. Ruffino, P. Soardo and G. Toselli, High Temp.-High Press. 5 , 99-104 (1973).

58. Ya. M. Geda and V. N. Snopko, Teplofiz. Vysok. Temp. 19, 1260-1265 (1981); High Temp. $19,912-916$ (1981).

59. H. Luhleich, D. Seeberger, L. Sutterlin and R. V. Seggern, High Temp.-High Press. $\underline{9}$, 283-290 (1977).

60. L. Coslovi, F. Righini and A. Rosso, Alta Frequenza 44, 592-596 (1975).

61. A. N. Kolesnichenko, I. I. Petrova, A. I. Samsonov and V. Ya. Chekhovskoi, Teplofiz. Vysok. Temp. 20, 114-118 (1982); High Temp. 20, 106-109 (1982).

62. R. W. Ohse, J.-F. Babelot, P. R. Kinsman, K. A. Long and J. Magill, High Temp.-High Press. 11, 225-239 (1979).

63. E. K. Storms and B. A. Mueller, J. Phys. Chem. 82, 51-59 (1978).

64. P. D. Garn, Thermoanalytical Methods of Investigation, Academic Press, New York (1965).

65. D. Schultze, Differentialthermoanalyse, Verlag Chemie, Weinheim (1969).

66. D. E. Etter, P. A. Tucker and L. J. Wittenberg, Thermal Analysis, Academic Press, New York (1969).

67. R. C. Mackenzie (ed.), Differential Thermal Analysis, 1 (1970); 2 (1972); Academic Press, London.

68. T. Daniels, Thermal Analysis, Kogan Page, London (1973).

69. A. Blažek, Thermal Analysis, Van Nostrand-Reinhold, London (1974).

70. W. W. Wendlandt, Thermal Methods of Analysis, Wiley, New York (1974).

71. W. W. Wendlandt and L. W. Collins, Thermal Analysis, Wiley, Chichester (1977).

72. K. Heide, Dynamische Thermische Analysenmethoden, VEB Deutscher Verlag fur Grundstoffindustrie, Leipzig (1979).

73. N. Smajić, Thermal Analysis, Proc. 6th ICTA, ed. W. Hemminger, Birkhauser, Basel, $\underline{2}$, 49-53 (1980).

74. A. Palenzona and P. Manfrinetti, J. Less-Common Met. 85, 307-312 (1982).

75. S. Cirafici, A. Palenzona and P. Manfrinetti, J. Less-Common Met. 90, 49-56 (1983).

76. E. Kaldis, B. Fritzler and W. Peteler, z. Naturforsch. 34a, 55-67 (1979).

77. M. N. Abdusalyamova, O. R. Burnashev and K. E. Mironov, J. Less-Common Met. 77, 81-88 (1981).

78. S. P. Yatsenko, A. A. Semyannikov, H. O. Shakarov and E. G. Fedorova, J. Less-Common Met. $90,95-108$ (1983).

79. R. Flükiger, Ch. Susz, F. Heiniger and J. Muller, J. Less-Common Met. 40,103-119(1975).

80. R. Flủkiger, J.-L. Staudenmann and P. Fischer, J. Less-Common Met. $50,253-273$ (1976).

81. J. L. Jorda, R. Flükiger and J. Muller, J. Less-Common Met. 55, 249-264 (1977).

82. H. D. Heetderks, E. Rudy and T. Eckert, Planseeber. Pulvermet. 13, 105-125 (1965).

83. J. L. Caslavsky and D. J. Viechnicki, J. Mat. Sci. 15, 1709-1718 (1980).

84. O. Knotek, E. Lugschneider, H. Reimann and H. G. Sasse, Metall $35,130-132$ (1980).

85. J. L. Jorda, R. Flükiger and J. Muller, J. Mat. Sci. $13, \overline{2471-2476}$ (1978).

86. J. L. Jorda, R. Flükiger and J. Muller, J. Less-Common Met. 62, 25-37 (1978).

87. H.-L. Lukas and W. Hemminger, Thermochim. Acta 22, 283-288 (1978).

88. M. C. Lee and I. Feng, Rev. Sci. Instrum. 53, 854-859 (1982).

89. W. A. Oran and L. H. Berge, Rev. Sci. Instrum. 53, 851-853 (1982).

90. P. C. Nordine and R. M. Atkins, Rev. Sci. Instrum. 53, 1456-1464 (1982).

91. M. B. Ouaida and J. M. Badie, J. Phys. E 15, 941-944 (1982).

92. D. Schultze, Thermochim. Acta 29, 233-242 (1979).

93. A. A. Kaminskij, S. E. Sarkisov, J. Bohm, P. Reiche, D. Schultze and R. Uecker, Phys. Stat. Sol. 43a, 71-79 (1977).

94. J. Bohm, R. Schalge, D. Schultze and C. Waligora, Kristall Technik 13, 423-428 (1978). 
95. G. M. Clark, Thermochim. Acta 27, 19-25 (1978).

96. G. M. Clark and R. Garlick, Thermochim. Acta 34, 365-375 (1979).

97. K. Lфnvik, Thermal Analysis, Proc. 4th ICTA, ed. I. Buzás, Akadémiai Kiadó, Budapest, 3, 1089-1093 (1975).

98. R. L. Rose, J. Phys E 12, 13-14 (1979).

99. M. Müller and H.-J. Güntherodt, J. Phys. E 14, 453-456 (1981).

100. F. Schlawne, K. Kühnreich, H. W. Schöpgens and H. Alexander, IEEE Trans. Magnetics 16 , 262-265 (1980).

101. J. Valenzuela and A. E. Miller, Rev. Sci. Instr. 48, 191-193 (1977).

102. S. Roitti, J. Mat. Sci. Lett. $1, \overline{217-218(1982)}$.

103. F. Ordway and T. F. Newkirk, Ceram. Age 58, 28-35 (1951).

104. M. G. Day and A. Hellawell, J. Inst. Met. 93, 276-284 (1965).

105. I. Shindo, J. Cryst. Growth 50, 839-851 (1980).

106. F. J. J. Van Loo, F. M. Smet, G. D. Rieck and G. Verspui, High Temp.-High Press. 14, 25-31 (1982).

107. R. Castanet, C. Bergman and J.-C. Mathieu, Calphad 3, 205-222 (1979).

108. R. Castanet, Thermochim. Acta 37, 259-260 (1980).

109. W. Schuster, J. Ipser and K. L. Komarek, Monatsh. Chem. 110, 1171-1188 (1979).

110. H. Ipser, Z. Metallkde. 73, 151-158 (1982).

111. W. Weppner, Ch. Li-Chuan and W. Piekarczyk, z. Naturforsch. 35a, 381-388 (1980).

112. W. Weppner, Ch. Li-Chuan and A. Rabenau, J. Solid State Chem. 31, 257-264 (1980).

113. H. N. Tran, C. So, D. J. Miller and D. Barham, Thermal Analysis, Proc. 7th ICTA, ed. B. Miller, Wiley, Chichester 1, 765-768 (1982).

114. R. Hultgren, P. D. Desai, D. T. Hawkins, M. Gleiser and K. K. Kelley, Selected Values of the Thermodynamic Properties of Binary Alloys, ASM, Metals Park, Ohio (1973).

115. O. Kubaschewski and C. B. Alcock, Metallurgical Thermochemistry, Pergamon Press, Oxford (1979).

116. W. Hemminger and G. Höhne, Grundlagen der Kalorimetrie, Verlag Chemie, Weinheim (1979).

117. A. Navrotsky, Phys. Chem. Miner. 2, 89-104 (1977).

118. O. J. Kleppa, in: Calculation of Phase Diagrams and Thermochemistry of Alloy Phases, eds. Y. A. Chang and J. F. Smith, AIME, Warrendale, Pa. , 213-228 (1979).

119. O. Kubaschewski, Thermochim. Acta 22, 199-209 (1978).

120. B. Predel and I. Arpshofen, Thermochim. Acta 22, 211-236 (1978).

121. A.-M. Zahra and M. Laffitte, Analysis $6,133-\overline{14} 4$ (1978).

122. O. J. Kleppa and K. C. Hong, J. Chem. Thermodyn. 10, 243-248 (1978).

123. K. C. Hong and O. J. Kleppa, J. Chem. Thermodyn. $\frac{10}{10}, 797-802$ (1978).

124. C. Picard and P. Gerdanian, J. Solid State Chem. 14, 66-77 (1975).

125. G. Boureau and P. Gerdanian, Acta Metall. 24, 717-723 (1976).

126. G. Boureau, O. J. Kleppa and P. Dantzer, J. Chem. Phys. 64, 5247-5254 (1976).

127. G. Boureau and O. J. Kleppa, J. Chem. Phys. 65, 3915-3920 (1976).

128. P. Dantzer and O. J. Kleppa, J. Solid State Chem. 24, 1-9 (1978).

129. P. Dantzer and O. J. Kleppa, J. Solid State Chem. $35,34-42$ (1980).

130. O. J. Kleppa, Ber. Bunsenges. Phys. Chem. 87, 741-749 (1983).

131. K. J. Dickens, O. J. Kleppa and H. Yokokawa, Rev. Sci. Instrum. 51, 675-676 (1980).

132. P. Dantzer and A. Guillot, J. Phys. E 15, $1373-1375$ (1982).

133. M. Gaune-Escard and J.-P. Bros, Can. Met. Quart. 13, 334-338 (1974).

134. I. Arpshofen, B. Predel and E. Schultheiss, Thermochim. Acta 33, 197-209 (1979).

135. G. Hatem, P. Gaune, J.-P. Bros, F. Gehringer and E. Hayer, Rev. Sci. Instrum. 52, 585-589 (1981).

136. G. Oehme and B. Predel, Thermochim. Acta 22, 267-273 (1978).

137. B. Predel and E. Gerdes, J. Less-Common Met. 59, 153-164 (1978).

138. Th. Hoster and O. Kubaschewski, Thermochim. Acta $40,15-18$ (1980.

139. W. A. Dench, Trans. Faraday Soc. 59, 1279-1292 (1963).

140. O. Kubaschewski and J. Grundmann, Ber. Bunsenges. Phys. Chem. 81, 1239-1242 (1977).

141. R. Lück and B. Predel, Hauptversammlung der Deutschen Gesellschaft für Metallkunde, 1.-4.6.1982, Villach, Austria.

142. B. Predel and R. Mohs, Arch. Eisenhuttenwes. 41, 61-66 (1970).

143. G. Betz and M. G. Frohberg, Metall 35, 299-303 (1981).

144. Y. Takahashi, H. Yokokawa, H. Kadokura, Y. Sekine and T. M. Mukaibo, J. Chem. Thermodyn. 11, 379-394 (1979).

145. E. E. Shpilrain, D. N. Kagan and S. N. Ulyanov, Teplofiz. Vys. Temp. 18, 1184-1190 (1980) .

146. E. E. Shpilrain, D. N. Kagan and S. N. Ulyanov, Teplofiz. Vys. Temp. 19, 1040-1044 (1981); High Temp. 19, 882-887 (1981).

147. J. W. Shaner, G. R. Gathers and C. Minichino, High Temp.-High Press. 9, 331-343 (1977).

148. K. Naito, H. Inaba, M. Ishida and K. Seta, J. Phys. E 12, 712-718 (1979).

149. A. Inaba, J. Chem. Thermodyn. 15, 1137-1143 (1983).

150. W. M. Cash, E. E. Stansbury, C. F. Moore and C. R. Brooks, Rev. Sci. Instrum. 52, 895901 (1981).

151. J. Rogez and J. LeCoze, Rev. Phys. Appl. 15, 341-351 (1980).

152. M. Braun and R. Kohlhaas, Phys. Status Solidi 12, 429-444 (1965).

153. G. Betz and M. G. Frohberg, High Temp.-High Press. 12, 169-178 (1980). 
154. G. Betz and M. G. Frohberg, Z. Metallkd. 71, 451-455 (1980).

155. A. Janitsch, K. L. Komarek and J. Mikler, Z. Metallkd. 71, 629-634 (1980).

156. S. C. Mraw and D. F. Maas, J. Chem. Thermodyn. $11,567-\overline{58} 4$ (1979).

157. R. T. Marano, Thermochim. Acta 26, 27-37 (1978).

158. Z. Moser, in: see Ref. 118, p. 242-274.

159. D. A. R. Kay, Rev. Int. Hautes Tempér. Réfract. 16, 21-32 (1979).

160. S. Geller (ed.), Solid Electrolytes, Top. Appl. Phys. 21 (1977).

161. E. C. Subarao (ed.), Solid Electrolytes and Their Applications, Plenum Publ. Corp., New York (1980).

162. A. M. Anthony, J. F. Baumard and J. Corish, J. Pure Appl. Chem., to be published.

163. M. Rand, IUPAC Commission II.3

164. K. T. Jacob and M. Iwase, High Temp. Science 16, 123-129 (1983).

165. C. B. Alcock, in: High Temperature Chemistry of Inorganic and Ceramic Matexials, eds. F. P. Glasser and P. E. Potter, The Chemical Soc., Spec. Publ. \#30, 116-133 (1977).

166. D. Janke and W. A. Fischer, Arch. Eisenhüttenwes. 48, 255-260 (1977).

167. D. Janke and K. Schwerdtfeger, Stahl u. Eisen 98, 825-829 (1978).

168. D. Janke and H. Richter, Arch. Eisenhüttenwes. 50, 93-100 (1979).

169. M. Kawakami, K. S. Goto and M. Matsuoka, Met. Trans. 11B, 463-469 (1980).

170. D. Janke, Metall. Trans. 13B, 227-235 (1982)

171. W. Worrell, private communication

172. K. T. Jacob, Metall. Trans. 13B, 283-285 (1982).

173. K. T. Jacob and M. Iwase, Z. Metallkd. 73, 316-320 (1982).

174. C. B. Alcock, K. Fitzner and K. T. Jacob, J. Chem. Thermodyn. 9, 1011-1020 (1977).

175. M. Rivier and A. D. Pelton, J. Electrochem. Soc. $125,1377-1382$ (1978).

176. S. Tamaki and N. E. Cusack, J. Phys. F 9, 403-412 (1979).

177. P. Gray, N. E. Cusack, S. Tamaki and Y. Tsuchiya, Phys. Chem. Liqu. 9, 307-321 (1980).

178. H. Hoshino and H. Endo, Solid State Commun. 36, 423-425 (1980).

179. H. Fischbach, Z. Metallkd. 71, 448-450 (1980).

180. J. A. Little and D. J. Fray, Trans. Inst. Min. Met. Sect. C, 88, C229-C233 (1979).

181. G. C. Farrington and B. Dunn, Solid State Ionics 7, 267-281 (1982).

182. G. C. Farrington, B. Dunn and J. O. Thomas, Appl. Phys. A32, 159-161 (1983).

183. H. Kleycamp, Ber. Bunsenges. Phys. Chem. 87, 777-781 (1983).

184. J. Delcet, A. Delgado-Brune and J. J. Egan, in: see Ref. 118, p. 275-286.

185. R. G. Coltters and G. R. Belton, Metall. Trans. 11B, 525-529 (1980).

186. K. T. Jacob, D. B. Rao and H. G. Nelson, J. Electrochem. Soc. 125, 758-762 (1978).

187. T. A. Ramanarayanan and W. L. Worrell, J. Electrochem. Soc. 127, 1717-1721 (1980).

188. Q. G. Liu and W. L. Worrell, in: Chemical Metallurgy - Tribute to Carl Wagner, ed.

N. A. Gokcen, AIME, Warrendale, Pa., 43-49 (1981).

189. J. W. Hastie (ed.), NBS Spec. Publ. 561 (1979).

190. E. D. Cater, see Ref. 189, p. 3-38

191. C. Chatillon, M. Allibert and A. Pattoret, see Ref. 189, p. 181-210

192. M. Allibert, C. Chatillon and R. Lourtau, Rev. Int. Hautes Tempér. Réfract. 16, 33-37 (1979).

193. H. E. Peltner and Ch. Herzig, Phys. Status Solidi (a), 48, K79-K81 (1978).

194. J. G. Edwards, see Ref. 189, p. 67-81

195. J. G. Edwards, M. K. Heckler and H. B. Thompson, Rev. Sci. Instrum. 50, 374-377 (1979).

196. H. B. Thompson and J. G. Edwards, J. Vac. Sci. Technol. 17, 117-119 (1980).

197. M. Allibert and C. Chatillon, Rev. Int. Hautes Temper. Refract. 17, 271-294 (1980).

198. G. R. Belton and R. J. Fruehan, J. Phys. Chem. 71, 1403-1409 (1967).

199. A. Neckel and S. Wagner, Ber. Bunsenges. Phys. Chem. 73, 210-217 (1969).

200. N. W. K. Liu and D. W. Muenow, High Temp. Science 10, 145-153 (1978).

201. M. E. Paulaitis and C. A. Eckert, J. Chem. Thermodyn. 15, 55-64 (1983). 